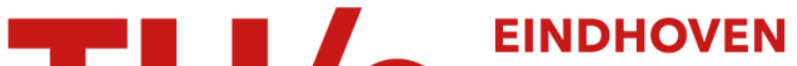 \\ UNIVERSITY OF \\ TECHNOLOGY
}

\section{Iterative solution of field problems with a varying physical parameter}

Citation for published version (APA):

Tijhuis, A. G., Beurden, van, M. C., \& Zwamborn, A. P. M. (2006). Iterative solution of field problems with a varying physical parameter. In A. M. Anile, G. Ali, \& G. Mascali (Eds.), Scientific Computing in Electrical Engineering (pp. 253-257). (Mathematics in Industry; Vol. 9, partllI). Springer. https://doi.org/10.1007/978-3-54032862-9_36

DOI:

10.1007/978-3-540-32862-9_36

Document status and date:

Published: 01/01/2006

\section{Document Version:}

Publisher's PDF, also known as Version of Record (includes final page, issue and volume numbers)

\section{Please check the document version of this publication:}

- A submitted manuscript is the version of the article upon submission and before peer-review. There can be important differences between the submitted version and the official published version of record. People interested in the research are advised to contact the author for the final version of the publication, or visit the $\mathrm{DOI}$ to the publisher's website.

- The final author version and the galley proof are versions of the publication after peer review.

- The final published version features the final layout of the paper including the volume, issue and page numbers.

Link to publication

\section{General rights}

Copyright and moral rights for the publications made accessible in the public portal are retained by the authors and/or other copyright owners and it is a condition of accessing publications that users recognise and abide by the legal requirements associated with these rights.

- Users may download and print one copy of any publication from the public portal for the purpose of private study or research.

- You may not further distribute the material or use it for any profit-making activity or commercial gain

- You may freely distribute the URL identifying the publication in the public portal.

If the publication is distributed under the terms of Article $25 \mathrm{fa}$ of the Dutch Copyright Act, indicated by the "Taverne" license above, please follow below link for the End User Agreement:

www.tue.nl/taverne

Take down policy

If you believe that this document breaches copyright please contact us at:

openaccess@tue.nl

providing details and we will investigate your claim. 


\title{
Iterative Solution of Field Problems with a Varying Physical Parameter
}

\author{
A. G. Tijhuis ${ }^{1}$, M. C. van Beurden ${ }^{1}$ and A. P. M. Zwamborn ${ }^{2}$ \\ 1 Faculty of Electrical Engineering, Eindhoven University of Technology - P.O. Box 513, 5600 MB Eindhoven, \\ the Netherlands \\ 2 TNO Physics and Electronics Laboratory - P.O. Box 96864, 2509 JG 's-Gravenhage, the Netherlands.
}

\begin{abstract}
In this paper, linear field problems with a varying physical parameter are solved with the conjugate gradient method and a dedicated extrapolation procedure for generating the initial estimate. The scheme is formulated in detail. and its application to three-dimensional scattering problems for a rectangulas conducting plate and an inhomogeneous, dispersive dielectric body are discussed.
\end{abstract}

\section{Introduction}

In modern society different tuends are recognized in the usage of the available electromagnetic spectrum. One can think of wireless communication or transport of (digital) information. The density of such applications is increasing rapidly. Obtaining electromagnetic compatibility and/or reducing electromagnetic interference sometimes seems to be an impossibje task. Another trend is found in electromagnetic inverse scattering and profiling. For example, this development is used in the detection and classification of land mines and other unexploded ordnance. Regarding electromagnetic inversion, one can also think of medical applications such as tomography or the detection of defects in metallic heart valves. Finally, we would like to mention the problem of electromagnetic coupling into humans in the area of clinical hyperthermia or non-ionizing radiation hazards analysis. In these applications, a rigorous electromagnetic analysis is indispensable.

The focus of this chapter is found in computational tools in the field of electromagnetic analysis and design. One can identify the roadmap "going from engineering electromagnetics to electromagnetic engineering". One of the extensively used and most versatile methods is the integral equation technique. It takes into account that the iradiated object is present in free space and that it manifests itself through the presence of secondary sources or contrast sources. Integral equations can be solved by the method of moments [1]. This leads to a system of linear a]gebraic equations.

To solve this system, one can use direct discrete numerical solution methods, such as Gaussian Elimination or Singular Value Decomposition, or suitable iterative techniques such as a conjugate gradient (CG) method. An overview of numerical solution methods for linear systems of equations can be found in the book by Golub and Van Loan [2]. In electromagnetic scattering and coupling problems, integral equations are often solved by using a Fast Fourier Transform to compute the spatial convolution of the integral operator and a conjugate gradient iterative scheme. This so-called CGFFT method has been used successfully for many electromagnetic scattering and coupling problems $[3,4,5,6,7,8,9]$.

In analysis or design procedures, the engineer has the freedom to change one or more parameters to obtain an optimal design with respect to performance and costs. This means that he or she will need to consider the determination of electromagnetic fields for a (large) number of values of a physical parameter. In this chapter we present a strong approach for this type of problem, which utilizes the iterative schemes mentioned above. We restrict ourselves to the case where the linear system originates from one or more integral equations. We apply an iterative procedure based on the minimization of an integrated squared error, and start this procedure from an initial estimate that is a linear combination of the last few "final" results. When the coefficients in this extrapolation are determined by minimizing the integrated squared ertor for the actual value of the parameter, the built-in orthogonality in this type of scheme ensures that only a few iteration steps are required to obtain the solution. The success of this strategy has been demonstrated before $[10,11,12]$. However, it has not been applied to 3-D problems.

The outline of the chapter is as follows. In Sect. 2, the method of solution is discussed. Special attention is given to the iterative procedure and the implementation of a relevant initial estimate based on the previous solutions. Explicit examples are discussed in Sect. 4 and Sect. 5 presents the conclusions. 


\section{Method of Solution}

In the computational modeling of electromagnetic fields for practical applications, typically a large system of linear equations must be solved. This system originates from spatially discretizing Maxwell's differential equations (in "finite" or "local" techniques) or equivalent integral equations (in "global" techniques). In formal notation, such a system can be written as

$$
L(p) u(p)=f(p),
$$

where

$$
\begin{aligned}
L(p) & =\text { a linear operator, } \\
u(p) & =\text { the unknown field, } \\
f(p) & =\text { the forcing function, } \\
p & =\text { a physical parameter. }
\end{aligned}
$$

The operator $L(p)$ originates from discretizing its counterpart in the continuous equation, $u(p)$ is a discretized field and $f(p)$ corresponds to an impressed source or an incident field. We are interested in the situation where this problem must be solved for a large number of sampled values of the parameter $p$, e.g. $p_{m}=p_{0}+m \Delta p$, with $m=0,1, \ldots, M$.

To solve the system of equations (1), we use the conjugate gradient method. This algorithm is described in detail by Van den Berg [3, 4]. Further, we organize the space discretization such that the convolution structure of the continous equation is preserved In that case, the matrix-vector products in the CG algorithm can be evaluated by FFT operations, equation is preserved. In that case, the matrix-vector products in the CG algorithm can be evalued
which considerably improves the speed of the so-called CGFFT algorithm [3, $[3,5,6,7,8,9]$.

In many applications of the conjugate gradient method, a simple initial estimate is used. Typically, the scheme is started from an initial vector $u^{(0)}=0$. Depending on the nature of the problem at hand, we can also start from an incident field or from the Kirchhoff approximation to an unknown surface current.

Our choice of the initial estimate is inspired by the fact that $u(p)$ depends in a well-behaved manner on the parameter $p$. Therefore, it should be possible to extrapolate, by choosing

$$
u^{(0)}\left(p_{m+1}\right)=\sum_{k=1}^{K} \gamma_{k} u\left(p_{m-k}\right)
$$

The interpretation of the conjugate gradient scheme given above suggested that the values $\left\{\gamma_{k} \mid k=1, \ldots, K\right\}$ should be found by minimizing the squared error

$$
<L\left(p_{m}\right) u^{(0)}\left(p_{m}\right)-f\left(p_{m}\right) \mid L\left(p_{m}\right) u^{(0)}\left(p_{m}\right)-f\left(p_{m}\right)>
$$

where we have defined the inner product as

$$
<g \mid h>=\sum_{j} g_{j}^{*} h_{j},
$$

where $g_{j}$ and $h_{j}$ denote the components of $g$ and $h$, and where the asterisk denotes complex conjugation.

Because of the built-in orthogonality of the conjugate gradient method, we are then certain that this procedure must start its search for components of $f\left(p_{m}\right)$ outside the space spanned by the "previous" functions $\left\{L u\left(p_{n-k}\right) \mid k=\right.$ $1, \ldots, K\}$.

The coefficients $\gamma_{k}$ that minimize the squared error in (3) can be found from the system of linear equations

$$
\sum_{k^{\prime}=1}^{K}<L\left(p_{m}\right) u\left(p_{m-k}\right) \mid L\left(p_{m}\right) u\left(p_{m-k^{\prime}}\right)>\gamma_{k^{j}}
$$

$$
=<L\left(p_{m}\right) u\left(p_{m-k}\right) \mid f\left(p_{m}\right)>,
$$

with $k=1, \ldots, K$. Typically, we choose $K=2$ (Ginear extrapolation) or $K=3$ (quadratic extrapolation). For larger values of $K$, the basis vectors $L\left(p_{m}\right) u\left(p_{m-n}\right)$ with $n=1, \ldots, K$ become almost linearly dependent, and therefore the coefficients $\left\{\gamma_{k}\right\}$ can no longer be resolved from (5).

\section{Scattering by Three-Dimensional Objects}

To illustrate our approach, we have extended existing implementations of the CGFFT procedure for two threedimensional objects that have become standards in the literature. In both cases, no special precautions were taken to enhance the discretization, which is first-order accurate as a function of the mesh size.
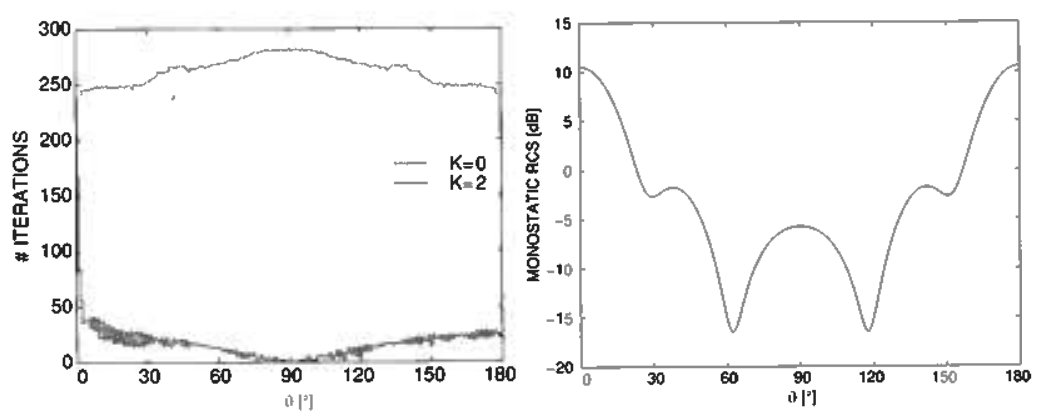

Fig. 1. Marching-on-in-angle version of the CGFFT method for a fat plate. (a) Number of iterations required to reach a relative error of $10^{-3}$ versus angle of incidence using zero (gray line) and two previous results (black line) as an initial estimate. (b) Monostatic radar cross section versus angle of incidence

\subsection{Scattering by a Flat Plate}

The first example is a flat, rectangular plate in free space located at $0<x<a, 0<y<b$ and $z=0$. For this problem, we solve the well-known electric-field integral equation

$$
\begin{array}{r}
{\left[\nabla_{\mathrm{T}} \nabla_{\mathrm{T}} \cdot-\frac{s^{2}}{c_{0}^{2}}\right] \int_{0}^{a} d x^{\prime} \int_{0}^{b} d y^{\prime} \frac{\exp \left(-s R / c_{0}\right)}{4 \pi R} J_{\mathrm{S}}\left(\boldsymbol{r}_{\mathrm{T}}^{\prime}, s\right)} \\
=-s \varepsilon_{0} \boldsymbol{E}_{\mathrm{T}}^{\mathrm{T}}\left(\boldsymbol{r}_{\mathrm{T}}, s\right)
\end{array}
$$

where $s$ is a complex frequency, $R-\left|r_{\mathrm{T}}-r_{\mathrm{T}}^{\prime}\right|$, and where the subscript $\mathrm{T}$ stands for a transverse component The unknown surface current $J_{S}\left(r_{\mathrm{T}}, s\right)$ is approximated by rooftop functions, and we use a weak formulation of $(6)$, weighted by the same rooftop functions [13]. In the resulting discretized form, the convolution symmetry is preserved, so that the matrix-vector products in the conjugate gradient procedure can be evaluated with the aid of two-dimensional FFT operations.

In particular, we have computed the monostatic radar cross section of a $\lambda \times \lambda$ plate for the special case $s=j \omega$. A plane wave is incident on the plate at an angle $\vartheta$ with respect to the $z$-axis and an angle $\phi=90^{\circ}$ with respect to the $x$-axis. The incident plane wave is $x$-polarized. The discretized plate has a mesh of $31 \times 31$ points. Figure 1 (a) shows the number of iterations for increasing $\vartheta$. In the generic formulation of Section 2, this means that $p=\vartheta$. The gray line the number of iterations for increasing $\vartheta$. In the generic formulation of Section 2 , this means that $p=v$. The gray line $K=2$. Figure 1 presents the monostatic radar cross section of the $\lambda \times \lambda$ plate in the plane $\phi=90^{\circ}$.

Another result for the plate concerns marching on in length. Now, the parameter $p$ represents the length of the plate in the $\tau$-direction. The idea was inspired by the shape sensitivity analysis in $[14,15]$. Here, we start from a $\lambda \times \lambda$ plate and we increase the length of the plate in 100 steps to a $2 \lambda \times \lambda$ plate. We used a fixed spatial discretization of $62 \times 31$ mesh points. The number of iterations required to reach a relative error of $10^{-3}$ versus the length of the plate is shown in Fig. 2. In the computations leading to Figs. 1 and 2, it turned out that extrapolation with $K=2$ was in fact more efficient than extrapolation with $K=3$

\subsection{Scattering by an Inhomogeneous Dielectric Cube}

The second example is an inhomogeneous dielectric cube, again in free space. We formulate the scattering problem as a domain integral equation over the object domain $\mathcal{D}$ as

$$
\boldsymbol{E}^{i}(\boldsymbol{r}, s)=\frac{D(r, s)}{\varepsilon(\boldsymbol{r}, s)}+\left(\frac{s^{2}}{c_{0}}-\nabla \nabla \cdot\right) \boldsymbol{A}(\boldsymbol{r}, s)
$$

where $s$ is a complex frequency and where the vector potential $\boldsymbol{A}(\boldsymbol{r}, s)$ is given by

$$
\boldsymbol{A}(\boldsymbol{r}, s)=\frac{1}{\varepsilon_{0}} \iiint_{\mathcal{D}} \frac{\exp \left(-s R / c_{0}\right)}{4 \pi R} \frac{\varepsilon(r, s)-\varepsilon_{0}}{\varepsilon(r, s)} D(r, s) d V^{\prime},
$$

where $R=\left|r-r^{\prime}\right|$. We take the contrast function in (8) constant in each rectangular subdomain in the space discretization. Like the current in the plate problem, the dielectric displacement $D(r, s)$ is approximated by an expansion 


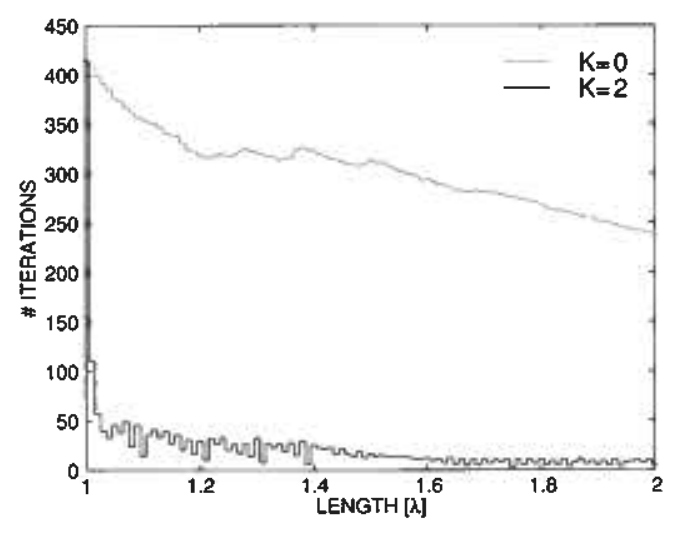

Fig. 2. Number of iterations required to reach a relative enror of $10^{-3}$ versus length of the plate for the marching Fig. 2. Number of iterations required to reach a relative enror of $10^{-3}$ versus length of the plate for the marching
on-in-length version of the CGFFT method for a flat plate using zero (gray line) and two previous results (black line) as an initial estimate

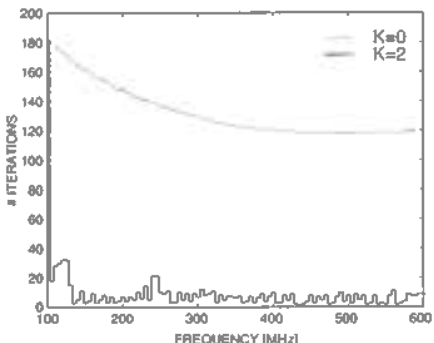

(a)

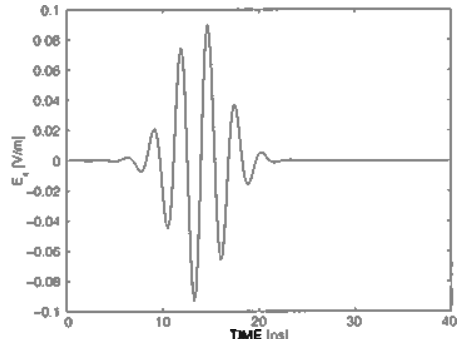

(b)
Fig. 3. Marching-on-in-frequency version of the CGFFT method for an inhomogeneous dielectric cube. (a) Number of Erations required to reach a relative error of $10^{-3}$ versus frequency for the using zero (gray line) and two previous results (black line) as an initial estimate. (b) Time domain signal at the center of the muscle cube for an incident results (black line) as an init
$x$-polarized wave of $1 \mathrm{~V} / \mathrm{m}$

that is piecewise linear in the longitudinal direction and constant in the transverse directions. The Green's function is replaced by a weak form, and the result is weighted by testing functions that are identical to the expansion functions. Again, the space discretization preserves the convolution symmetry of the continuous form of the integral equation given in (7) and (8). More details can be found in the papers by Zwamborn and Van den Berg [16, 17].

As an illustration, we have modeled a cube of muscle tissue centered inside a cube of fat tissue. The incident field is $x$-polarized with propagation vector parallel to the $z$-axis and a strength of $1 \mathrm{~V} / \mathrm{m}$. The dispersive tissues are modeled using a Debye model [18] and the dimensions of the inner and outer cubes are $0.14 \mathrm{~m}$ and $0.30 \mathrm{~m}$, respectively. The discretized object has $30 \times 30 \times 30$ mesh points. The field is computed in the middle of the muscle cube for real-valued frequencies $f=\omega / 2 \pi=-j s / 2 \pi$ of 100 to $600 \mathrm{MHz}$ and then converted to a time domain signal. In this case, we vary $p=\omega$. The number of itetations needed is shown in Fig 3(a), where the gray line is for a zero initial estimate and expolation procedure led to the most rapid convergence. The time signal, shown in Fig. 3(b), is computed by an FFT using the waveform $\exp \left[-(t-\tau)^{2} /\left(2 T^{2}\right)\right] \sin \left(\omega_{0} t\right)$, where $\tau=14 \mathrm{~ns}, T=2.75 \mathrm{~ns}$ and $\omega_{0} / 2 \pi=450 \mathrm{MHz}$

\section{Conclusions}

In this chapter, we have extended the conventional conjugate gradient method with a dedicated extrapolation procedure that considerably enhances the speed of convergence. Although the procedure has already been demonstrated successfully for a range of applications, including transient scattering, radar cross section computations and inverse profiling, until now no applications to three-dimensional configurations have been reported. In the present chapter, this gap has been filled.

\section{References}

1. Harrington, R.F: Field computation by Moment Methods. Macmillan, New York (1968)

2. Golub, G.H., and Van Loan, C.F.: Matrix Computations (Third Edition). The Johns Hopkins University Press, Baltimore (1996)

3. Van den Berg, P.M.: Iterative computational techniques in scattering based upon the integrated square error criterion. IEEE Trans. Antennas Propagat. 32 (1984) 1063-1071

4. Van den Berg, P.M.: Iterative schemes based on the minimization of the error in field problems. Electromagnetics 5 (1985) 237-262

5. Sarkar, T.K., Arvas, E. and Rao, S.M.: Application of the fast Fourier transform and the conjugate gradient method for the solution of electromagnetic radiation from electrically large and small conducting bodies. Electromagnetics 5 (1985) $99-122$

6. Bokhari, S.A., and Balakrishnan, N.A.: A method to extend the spectral iteration technique. IEEE Trans. Antennas Propagat. 34 (1986) 51-57

7. Sarkar, T.K. Arvas, E. and Rao, S.M.: Application of the FFT and the conjugate gradient method for the solution of electromagnetic radiation from electrically large and small conducting bodies. IEEE Trans. Antennas Propagat. 34 (1986) 635-640

8. Yuan Zhuang, Ke-Li Wu, Chen Wu and Litva, J.: A combined full-wave CGFFT method for rigorous analysis of large microstrip antenna arrays. IEEE Trans. Antennas Propagat, 44 (1996) 102-109

9. Basterrechea, J. and Catedra, M.F.: Computatation of microstrip S-parameter using a CG-FFT scheme, IEEE Trans. Microwave Theory Tech. 42 (1994) 234-240

10. Tijhuis, A.G., Peng, Z.Q. and Rubio Bretones. A.: Transient excitation of a straight thin wire segment: a new look at an old problem. IEEE Trans. Antennas Propagat. 40 (1994) 1132-1146

11. Tijhuis, A.G., and Peng, Z.Q.: Marching-on-in-fequency method for solving integral equations in transient electromagnetic scattering. IEE Proc. H 138 (1991) 347-355
trong

12. Peng, Z.Q. and Tijhuis, A.G.: Transient scattering by a lossy dielectric cylinder: marching-on-in-frequency approach. J. Electromagn. Waves Applicat. 7 (1993) 739-763

13. Zwamborn, A.P.M. and Van den Berg, P.M.: The weak form of the conjugate gradient method for plate problems. IEEE Trans. Antennas Propagat. 39 (1991) 224-228

14. Ureel, J and De Zutter, D. Shape sensitivities of capacitances of planar conducting surfaces using the method of moments. IEEE Trans. Microwave Theory Tech. 44 (1996) 198-207

15. Ureel, J. and De Zutter, D.: A new method for obtaining shape sensitivities of planar microstrip structures by a full-wave analysis, IEEE Trans. Microwave Theory Tech. 44 (1996) 249-260

16. Zwamborn, A.P.M. and Van den Berg, P.M.: The three-dimensional weak form of the conjugate gradient FFT method for solving scattering problems. IEEE Trans. Microwave Theory Tech. 40 (1992) 1757-1766

17. Zwamborn, A.P.M. and Van den Berg, P.M.: Computation of electromagnetic fields inside strongly inhomogeneous objects by the weak conjugate gradient FFT method. JOSA A 11 (1994) 1414-1421

18. Lepelaars, E.S.A.M.: Electromagnetic pulse distortion in living tissue. Med. Biol. Eng. Comput. 34 (1996) $213-$ 220 